\title{
Influence of Uniform Compression on the Temperature Dependence of the Pseudogap of Medium-Praseodymium-Doped $\mathrm{Y}_{1-x} \mathrm{Pr}_{x} \mathrm{Ba}_{2} \mathrm{Cu}_{3} \mathrm{O}_{7-\delta}$ Single Crystals
}

\author{
G. Ya. Khadzhai ${ }^{1}$ (D) A. Chroneos ${ }^{2,3} \cdot$ I. L. Goulatis ${ }^{1} \cdot$ S. N. Kamchatnaya ${ }^{1}$. \\ A. L. Chikina ${ }^{1} \cdot$ N. R. Vovk ${ }^{1} \cdot$ R. V. Vovk ${ }^{1}$ (D)
}

Received: 24 January 2021 / Accepted: 22 March 2021 / Published online: 28 April 2021

(c) The Author(s) 2021

\begin{abstract}
The effect of high pressure on the conductivity in the basal plane of HTSC single crystals of $\mathrm{Y}_{0.77} \mathrm{Pr}_{0.23} \mathrm{Ba}_{2} \mathrm{Cu}_{3} \mathrm{O}_{7-\delta}$ is investigated. It has been established that the excess conductivity, $\Delta \sigma(T)$, of these single crystals in a wide temperature range $T_{\mathrm{f}}<T<T^{*}$ can be described by an exponential temperature dependence. The description of the excess conductivity using the relation $\Delta \sigma \sim\left(1-T / T^{*}\right) \exp \left(\Delta *{ }_{a b} / T\right)$ can be interpreted in terms of the mean-field theory, where $T^{*}$ is represented as the temperature pseudogap opening, and the temperature dependence of the pseudogap (PG) is satisfactorily described in the framework of the BCS-BEC crossover theory. An increase in the applied pressure leads to the effect of narrowing the temperature interval for the realization of the PG-regime, thereby expanding the region of the linear dependence $\rho(T)$ in the $a b$-plane.
\end{abstract}

Keywords Excess conductivity $\cdot$ Hydrostatic pressure $\cdot$ YBaCuO single crystals · Substitution with praseodymium $\cdot$ Crossover $\cdot$ Pseudogap state

\section{A. Chroneos}

alexander.chroneos@imperial.ac.uk

1 Faculty of Physics, V.N. Karazin Kharkov National University, Svobody Sq. 4, Kharkov 61022, Ukraine

2 Department of Materials, Imperial College London, London SW7 2AZ, UK

3 Faculty of Engineering, Environment and Computing, Coventry University, Priory Street, Coventry CV1 5FB, UK 


\section{Introduction}

The study of the pseudogap anomaly (decrease in the density of states) continues to be one of the main directions of high-temperature superconductivity (HTSC) physics [1-3]. According to contemporary concepts [1, 2, 4], it is this unusual phenomenon, along with the fluctuation paraconductivity $[5,6]$, the metal-insulator transitions $[7,8]$, the incoherent charge transfer $[9,10]$, which are essential to understand the nature of HTSC [4].

Presently, the most debated scenarios for the realization of the PG state in HTSC cuprates are the concept of uncorrelated pairs $[2,3,11]$ and various models of dielectric fluctuations [1]. Among the theoretical works supporting the first point of view is the crossover theory from the Bardeen-Cooper-Schrieffer (BCS) mechanism to the Bose-Einstein condensation (BEC) mechanism [11], in which the temperature dependencies of the pseudogap were obtained for the case of weak and strong pairing. In general, these dependencies are described by equation:

$$
\Delta(T)=\Delta(0)-\Delta(0) \sqrt{\frac{\pi}{2}} \sqrt{\frac{T}{\Delta(0)}} \exp \left[-\frac{\Delta(0)}{T}\right] \times\left[1+\operatorname{erf}\left(\sqrt{\frac{\sqrt{x_{0}^{2}+1}-1}{T / \Delta(0)}}\right)\right],
$$

where $x_{0}=\mu / \Delta(0)$ ( $\mu$ is the chemical potential of the carrier system; $\Delta(0)$ is the energy gap at $T=0)$, and $\operatorname{erf}(x)$ is the error function. form:

In the limiting case $x_{0} \rightarrow \infty$ (weak pairing), analytical expression (1) takes the

$$
\Delta(T)=\Delta(0)-\Delta(0) \sqrt{2 \pi \Delta(0) T} \exp \left[-\frac{\Delta(0)}{T}\right]
$$

well known in the BCS theory. At the same time, for the limit of strong interactions in the 3-dimensional case $\left(x_{0}<-1\right)$, formula (1) is transformed into:

$$
\Delta(T)=\Delta(0)-\frac{8}{\sqrt{\pi}} \sqrt{x_{0}}\left(\frac{\Delta(0)}{T}\right)^{3 / 2} \exp \left[-\frac{\sqrt{\mu^{2} \Delta^{2}(0)}}{T}\right]
$$

Herewith, as it was shown in [2, 3, 12], with sufficiently high measurement accuracy, the values of the pseudogap in a wide temperature range can be determined from $\rho_{a b}(T)$ dependencies (electrical resistivity in the basal plane) at temperatures below a certain characteristic value $T^{*}$ (temperatures of the transition to the pseudogap state).

The most promising system for research is the 1-2-3 system HTSC compounds with partial replacement of yttrium with praseodymium $\left(\mathrm{Y}_{1-x} \mathrm{Pr}_{x} \mathrm{Ba}_{2} \mathrm{Cu}_{3} \mathrm{O}_{7}-{ }_{\delta}\right)$, due to two main reasons. Firstly, doping with praseodymium, in contrast to other rare-earth elements $[13,14]$, leads to a gradual suppression of the superconducting parameters of the compound $[15,16]$, which makes it possible to smoothly vary the 
electrical transport properties of the compound. Secondly, such a replacement allows keeping the oxygen stoichiometry of the compound practically unchanged $[15,17$, 18]. This, in turn, makes it possible to avoid the appearance of the so-called nonequilibrium state, which can be induced in oxygen-deficient $\mathrm{YBa}_{2} \mathrm{Cu}_{3} \mathrm{O}_{7-\delta}$ samples in the case of a sudden change in temperature [19, 20], aging [21, 22] or application of pressure $[23,24]$. In the latter case, this requires the use of special techniques that make it possible to separate the so-called actual [25, 26] and relaxation [2, 3, 23, 24] pressure effects. Notably, despite a quite large number of studies regarding the effect of pressure on various characteristics of 1-2-3 compounds, only a small part of them was obtained on the $\mathrm{Y}_{1-x} \mathrm{Pr}_{x} \mathrm{Ba}_{2} \mathrm{Cu}_{3} \mathrm{O}_{7-\delta}$ compounds [15] and the effect of pressure on the PG in such samples was not studied at all. In our previous works [27, 28], we studied the effect of pressure on the resistive transition to the superconducting state and the fluctuation conductivity at temperatures near the critical temperature $\left(T \geq T_{\mathrm{c}}\right)$. In the present study we investigate the effect of high hydrostatic pressure up to $11 \mathrm{kbar}$ on the temperature dependence of the pseudogap in $\mathrm{Y}_{1-x} \mathrm{Pr}_{x} \mathrm{Ba}_{2} \mathrm{Cu}_{3} \mathrm{O}_{7-\delta}$ single crystals with an average $(x \approx 0.23)$ concentration of praseodymium at temperatures far from the critical temperature $\left(T>>T_{\mathrm{c}}\right)$.

\section{Experimental methods}

The HTSC $\mathrm{Y}_{1-x} \mathrm{Pr}_{x} \mathrm{Ba}_{2} \mathrm{Cu}_{3} \mathrm{O}_{7-\delta}$ single crystals were grown by the solution-melt technology in a gold crucible, according to the procedure reported previously $[16,27,28]$. For the resistive studies, we used rectangular crystals with a size of $3 \times 0.5 \times 0.03 \mathrm{~mm}^{3}$. The smallest crystal size corresponded to the $c$-axis direction. The electrical contacts were created according to the standard 4-contact scheme by applying a silver paste to the crystal surface, followed by connecting silver conductors $0.05 \mathrm{~mm}$ in diameter and annealing for three hours at a temperature of $200{ }^{\circ} \mathrm{C}$ in an oxygen atmosphere. This procedure made it possible to obtain a contact resistance of less than one Ohm and to carry out resistive measurements at transport currents up to $10 \mathrm{~mA}$ in the $a b$-plane. The hydrostatic pressure was created in a piston-cylinder multiplier [24, 26-28]. The magnitude of the pressure was determined using a manganin manometer, and the temperature was determined with a copperconstantan thermocouple mounted in the outer surface of the chamber at the level of the sample position.

\section{Results and discussion}

Figure 1 shows the temperature dependences of the electrical resistivity measured at the orientation of the transport current $I \perp c\left(\rho_{a b}(T)\right)$ and at different pressures. It can be seen that as the applied pressure increases, the critical temperature of the sample increases and the electrical resistivity decreases, which is consistent with previous studies [15]. The application of pressure also leads to a significant (up to $47 \mathrm{~K})$ expansion of the linear portion of the $\rho_{a b}(T)$ dependence in the high-temperature region. The latter is reflected in a decrease in the temperature $T^{*}$, at which a 


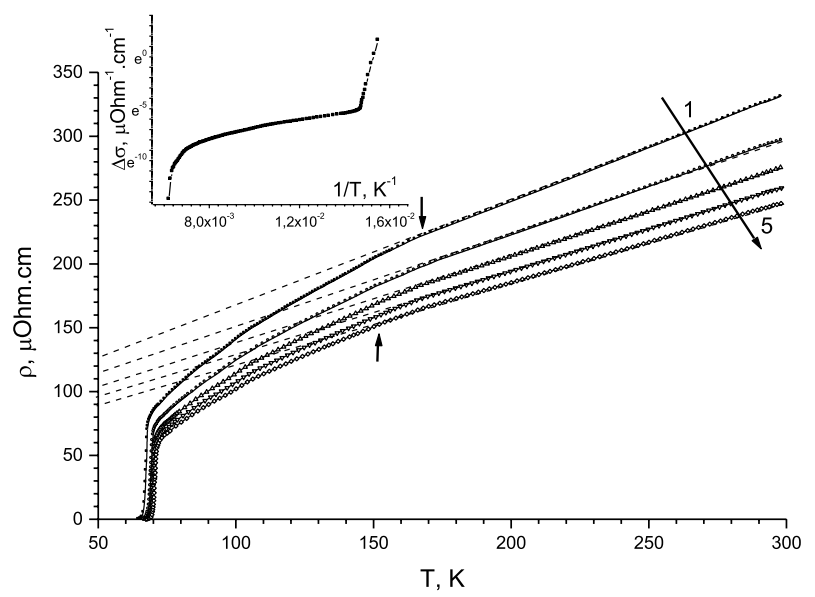

Fig. 1 Temperature dependences of the $\rho_{a b}(T)$ of the $\mathrm{Y}_{0.77} \mathrm{Pr}_{0.23} \mathrm{Ba}_{2} \mathrm{Cu}_{3} \mathrm{O}_{7-\delta}$ single crystal obtained at pressure: $0 ; 4.1 ; 6.4 ; 8.7 ; 11 \mathrm{kbar}$ - curves $1-5$, respectively. The arrows show the temperatures of the transition to the pseudogap state $T^{*}$. The inset shows the temperature dependences of the excess conductivity $\Delta \sigma(T)$ of the single crystal at atmospheric pressure

systematic deviation of the experimental points begins downward from the linear dependence. According to contemporary concepts, $T^{*}$ corresponds to the opening temperature of the pseudogap state [1-3], which will be discussed in more detail below.

A faster than a linear decrease in the value of $\rho_{a b}(T)$, which is observed in the temperature range $T<T^{*}$, indicates the appearance in the crystal of the so-called excess conductivity $(\Delta \sigma)$. The temperature dependence of excess conductivity is usually determined by:

$$
\Delta \sigma=\sigma-\sigma_{\text {lin }},
$$

where $\sigma_{\text {lin }}=\rho_{\text {lin }}{ }^{-1}=(A+B T)^{-1}$ is the conductivity determined by extrapolating the linear section to zero temperature, and $\sigma=\rho^{-1}$ is the experimental value of conductivity in the normal state.

The obtained experimental dependence $\Delta \sigma(T)$ is shown in the inset to Fig. 1 in $\ln \Delta \sigma-1 / T$ coordinates. It can be seen that in a relatively wide temperature range, these dependencies are linear, which corresponds to their description by an exponential dependence:

$$
\Delta \sigma \sim \exp \left(\Delta_{a b}^{*} / T\right)
$$

where $\Delta^{*}{ }_{a b}$ is a quantity that determines a specific thermoactivation process through an energy gap — the "pseudogap."

The exponential dependence $\Delta \sigma(\mathrm{T}, P=0)$ has already been observed earlier in $\mathrm{YBaCuO}$ film samples [12]. As shown in [12], the approximation of the experimental data can be substantially extended by introducing the factor $\left(1-T / T^{*}\right)$. In this case, the excess conductivity turns out to be proportional to the density of 
superconducting carriers $n_{s} \sim\left(1-T / T^{*}\right)$ and inversely proportional to the number of pairs $\sim \exp \left(-\Delta^{*} / k T\right)$ destroyed by the thermal motion:

$$
\Delta \sigma \sim\left(1-T / T^{*}\right) \exp \left(\Delta_{a b}^{*} / T\right) .
$$

wherein $T^{*}$ is considered as the temperature of occurrence (opening) of the pseudogap, and the temperature interval $T_{\mathrm{c}}<T<T^{*}$ in which the pseudogap state exists, is determined by the phase rigidity of the order parameter, which, in turn, depends on the oxygen deficiency or the concentration of the dopant. Thus, using the technique proposed previously [12], from the experimental curve $\ln \Delta \sigma$ it is possible to construct the temperature dependence $\Delta^{*}{ }_{a b}(T)$ up to $T^{*}$.

Figure 2 shows the temperature dependences of the pseudogap in $\Delta^{*}(T) / \Delta_{\text {мах }}-T / T^{*}$ coordinates $\left(\left(\Delta_{\text {мах }}\right.\right.$ is the value of $\Delta^{*}$ on a plateau far (away) from $\left.T^{*}\right)$ obtained at different pressures. Dependencies $\Delta^{*}(T) / \Delta(0)$ from $T / T^{*}$ that were calculated according to (2), (3) in the mean-field approximation in the framework of the BCS-BEC crossover theory [11] for the values of the crossover parameter $\mu / \Delta(0)=10$ (BCS border), -2, -5, -10 (BEC border) are shown in Fig. 2 with dashed lines. It can be seen that as the applied pressure increases, the experimental curves shift from dependences of the form (3) to (2). This behavior turns out to be qualitatively similar to the transformation of the temperature dependences of the pseudogap of the $\mathrm{YBaCuO}$ samples observed with a decrease in the degree of oxygen non-stoichiometry [2,3]. The correlations in the behavior of the curves $\Delta^{*}(T)$ are not random. In particular, as it is well known from previous studies (refer for example to [23-26]), the application of high pressure to the samples of the 1-2-3 HTSC system, as well as an increase in the oxygen content $[2,8]$, leads to an improvement in the conducting characteristics. This is expressed in an increase in the absolute value of $T_{c}$ and a significant decrease in

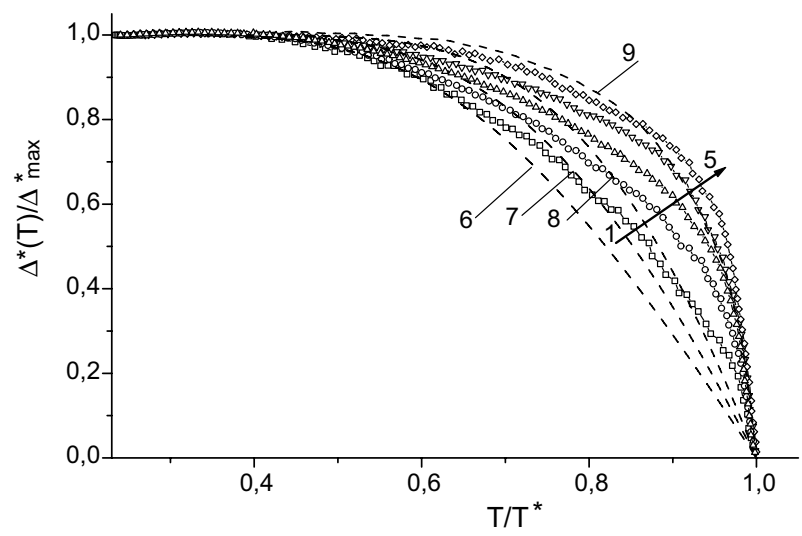

Fig. 2 Temperature dependences of the pseudogap of the $\mathrm{Y}_{0.77} \mathrm{Pr}_{0.23} \mathrm{Ba}_{2} \mathrm{Cu}_{3} \mathrm{O}_{7-\delta}$ single crystal in the $\Delta^{*}(T) / \Delta^{*}{ }_{\text {мах }}-T / T^{*}$ coordinates $\left(\Delta^{*}{ }_{\text {мах }}\right.$ is the value of $\Delta^{*}$ on the plateau far (away) from $\left.T^{*}\right)$. The numbering of curves corresponds to the numbering in Fig. 1. The dependences $\Delta^{*}(T) / \Delta(0)$ from $T / T^{*}$, calculated according to [11] for the values of the crossover parameter $\mu / \Delta(0)=10$ (BCS border), $-2,-5,-10$ (BEC border) are shown in Fig. 2 with dashed lines (6-9), respectively 
electrical resistivity. Herewith, specific mechanisms of structural relaxation and quasiparticle scattering [29-35], due to the presence of kinematic and structural anisotropy in the system, can have a certain effect. Thus, taking into account certain conventionality in determining the magnitude of the $T^{*}$ from the deviation of $\rho_{a b}(T)$ from linear behavior, the agreement between the experiment and theory in our case can be considered quite satisfactory.

\section{Conclusions}

Here we can conclude that the application of high pressure to $\mathrm{Y}_{1-\mathrm{x}} \mathrm{Pr}_{\mathrm{x}} \mathrm{Ba}_{2} \mathrm{Cu}_{3} \mathrm{O}_{7-\delta}$ $(\mathrm{x} \leq 0.23)$ single crystals leads to a significant expansion of the interval of the linear dependence $\rho_{a b}(T)$ and a narrowing of the temperature section of the implementation of the pseudogap state. Herewith, the excess conductivity obeys exponential temperature dependence in a wide temperature range, and the temperature dependence of the pseudogap is satisfactorily described within the framework of the BCS-BEC crossover theory.

Open Access This article is licensed under a Creative Commons Attribution 4.0 International License, which permits use, sharing, adaptation, distribution and reproduction in any medium or format, as long as you give appropriate credit to the original author(s) and the source, provide a link to the Creative Commons licence, and indicate if changes were made. The images or other third party material in this article are included in the article's Creative Commons licence, unless indicated otherwise in a credit line to the material. If material is not included in the article's Creative Commons licence and your intended use is not permitted by statutory regulation or exceeds the permitted use, you will need to obtain permission directly from the copyright holder. To view a copy of this licence, visit http://creativecommons.org/licen ses/by/4.0/.

\section{References}

1. T. Timusk, B. Statt, Rep. Prog. Phys. 62, 161 (1999)

2. R.V. Vovk, A.L. Solovyov, Low Temp. Phys. 44, 81 (2018). https://doi.org/10.1063/1.5020905

3. A.L. Solovjov, L.V. Omelchenko, R.V. Vovk, O.V. Dobrovolskiy, Z.F. Nazyrov, S.N. Kamchatnaya, D.M. Sergeyev, Phys. B 493, 58 (2016)

4. J. Ashkenazi, J. Supercond. Nov. Magn. 24, 1281 (2011)

5. T.A. Friedman, J.P. Rice, J. Giapintzakis, D.M. Ginzberg, Phys. Rev. B 39, 4258 (1989)

6. R.V. Vovk, N.R. Vovk, G.Y. Khadzhai, O.V. Dobrovolskiy, Z.F. Nazyrov, Curr. Appl. Phys. 14, 1779-1782 (2014)

7. K. Widdera, D. Bernera, H.P. Geserich, a, W. Widderb, H.F. Braunb // Physica C Volume 251, Issues 3-4 (1995), Pages 274-278.

8. R.V. Vovk, Z.F. Nazyrov, I.L. Goulatis, A. Chroneos, Physica C 485, 89-91 (2013)

9. P.W. Anderson, Phys. Rev. Lett. 67, 2092 (1991)

10. R.V. Vovk, M.A. Obolenskii, A.A. Zavgorodniy, I.L. Goulatis, A.I. Chroneos, J. Mater. Sci. Mater. Electron. 20, 858-860 (2009)

11. E. Babaev, H. Kleinert, Phys. Rev. B 59, 12083 (1999)

12. D.D. Prokof'ev, M.P. Volkov, Yu.A. Boikov, Phys. Solid State 45, 1223 (2003)

13. D.M. Ginsberg (ed.), Physical Properties High Temperature Superconductors I (World Scientific, Singapore, 1989) 
14. R.V. Vovk, M.A. Obolenskii, A.A. Zavgorodniy, I.L. Goulatis, A. Chroneos, E.V. Biletskiy, J. Alloys Compd. 485, 121-123 (2009)

15. M. Akhavan, Phys. B 321, 265 (2002)

16. R.V. Vovk, N.R. Vovk, G.Y. Khadzhai, I.L. Goulatis, A. Chroneos, Solid State Commun. 190, 18 (2014). https://doi.org/10.1016/j.ssc.2014.04.004

17. R.V. Vovk, N.R. Vovk, O.V. Shekhovtsov, I.L. Goulatis, A. Chroneos, Supercond. Sci. Technol. 26, 085017 (2013)

18. R.V. Vovk, N.R. Vovk, G.Y. Khadzhai, O.V. Dobrovolskiy, Solid State Commun. 204, 64-66 (2015)

19. J.D. Jorgencen, P. Shiyou, P. Lightfoot, H. Shi, A.P. Paulikas, B.M.W. Veal, Physica C 167, 571 (1990)

20. A.L. Solovjov, E.V. Petrenko, L.V. Omelchenko, R.V. Vovk, I.L. Goulatis, A. Chroneos, Sci. Rep. 9, 9274 (2019)

21. B. Martinez, F. Sandiumenge, S. Pinol, N. Vilalta, J. Fontcuberta, X. Obradors, Appl. Phys. Lett. 66(6), 772-774 (1995)

22. V. Vovk, N.R. Vovk, A.V. Samoilov, I.L. Goulatis, A. Chroneos, Solid State Commun. 170, 6-9 (2013)

23. R.P. Gupta, M. Gupta, Phys. Rev. B 51, 11760-11766 (1995)

24. D.D. Balla, A.V. Bondarenko, R.V. Vovk, M.A. Obolenskii, A.A. Prodan, Low Temp. Phys. 23, 777 (1997)

25. A.L. Solovjov, L.V. Omelchenko, E.V. Petrenko, R.V. Vovk, V.V. Khotkevych, A. Chroneos, Sci. Rep. 9, 20424 (2019). https://doi.org/10.1038/s41598-019-55959-1

26. R.V. Vovk, N.R. Vovk, G.Y. Khadzhai, I.L. Goulatis, A. Chroneos, Phys. B 422, $33-35$ (2013). https://doi.org/10.1016/j.physb.2013.04.032

27. G. Khadzhai, A. Matsepulin, R. Vovk, Effect of hydrostatic pressure up to 12 kbar on the electrical resistance of $\mathrm{Y}_{0.77} \mathrm{Pr}_{0.23} \mathrm{Ba}_{2} \mathrm{Cu}_{3} \mathrm{O}_{7-\delta}$ single crystals. LTP/FNT 47(2), 184-187 (2021)

28. G.Y. Khadzhai, N.R. Vovk, R.V. Vovk, Influence of uniform compression on fluctuation paraconductivity of $\mathrm{Y}_{0.77} \mathrm{Pr}_{0.23} \mathrm{Ba}_{2} \mathrm{Cu}_{3} \mathrm{O}_{7-\delta}$ single crystals, Low Temp. Phys. (in press)

29. N. Kuganathan, P. Iyngaran, R. Vovk, A. Chroneos, Sci. Rep. 9, 4394 (2019). https://doi.org/10. 1038/s41598-019-40878-y

30. N. Kuganathan, A. Kordatos, M.E. Fitzpatrick, R.V. Vovk, A. Chroneos, Solid State Ion. 327, 93-98 (2018)

31. A.J. Matthews, K.V. Kavokin, A. Usher, M.E. Portnoi, M. Zhu, J.D. Gething, M. Elliot, W.G. Herrenden-Harker, K. Phillips, D.A. Ritchie, M.B. Simmons, C.B. Sorensen, O.P. Hansen, O.A. Mironov, M. Myronov, D.R. Leadley, M. Henini, Phys. Rev. B 70, 075317 (2004)

32. P.G. Curran, V.V. Khotkevych, S.J. Bending, A.S. Gibbs, S.L. Lee, A.P. Mackenzie, Phys. Rev. B 84, 104507 (2011)

33. I.N. Adamenko, K.E. Nemchenko, V.I. Tsyganok, A.I. Chervanev, Low Temp. Phys. 20, 498 (1994)

34. O.V. Dobrovolskiy, V.M. Bevz, M.Yu. Mikhailov, O.I. Yuzephovich, V.A. Shklovskij, R.V. Vovk, M.I. Tsindlekht, R. Sachser, M. Huth, Nat. Commun. 9, 4927 (2018). https://doi.org/10.1038/ s41467-018-07256-0

35. O.V. Dobrovolskiy, R. Sachser, T. Brächer, T. Fischer, V.V. Kruglyak, R.V. Vovk, V.A. Shklovskij, M. Huth, B. Hillebrands, A.V. Chumak, Nat. Phys. 15, 477-482 (2019)

Publisher's Note Springer Nature remains neutral with regard to jurisdictional claims in published maps and institutional affiliations. 